University of New Hampshire

University of New Hampshire Scholars' Repository

University Library Scholarship

University Library

$10-1-2003$

\title{
Linking of errata: current practices in online physical sciences journals
}

\author{
Emily L. Poworoznek \\ University of New Hampshire
}

Follow this and additional works at: https://scholars.unh.edu/library_pub

Part of the Library and Information Science Commons

\section{Recommended Citation}

Poworoznek, E.L. Linking of errata: current practices in online physical sciences journals. Journal of the American Society for Information Science and Technology, 2003, v. 54, no. 12, pp. 1153-9.

This Article is brought to you for free and open access by the University Library at University of New Hampshire Scholars' Repository. It has been accepted for inclusion in University Library Scholarship by an authorized administrator of University of New Hampshire Scholars' Repository. For more information, please contact Scholarly.Communication@unh.edu. 
[Mss. as revised, 12/20/02; accepted for publication in the Journal

of the American Society for Information Science and Technology.]

Linking of Errata: Current Practices in Online Physical Sciences Journals

Emily L. Poworoznek

University of New Hampshire 


\begin{abstract}
Reader awareness of article corrections can be of critical importance in the physical and biomedical sciences. Comparison of errata and corrigenda in online versions of high-impact physical sciences journals across titles and publishers yielded surprising variability. Of 44 online journals surveyed, 14 had no links between original articles and later corrections. When present, hyperlinks between articles and errata showed patterns in presentation style, but lacked consistency. Variability in the presentation, linking, and availability of online errata indicates that practices are not evenly developed across the field. Comparison of finding tools showed excellent coverage of errata by $\underline{\text { Science Citation Index }}$, lack of indexing in INSPEC, and lack of

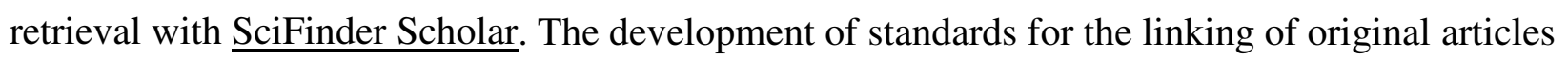
to errata is recommended.
\end{abstract}


Introduction

Errata, or corrections, are often published well after the original article, but can be vital to scientists using information from the original article. Since the 1980s, the National Library of Medicine has included fields for retractions, errata, and comments in the MEDLINE database entries for original articles (Kotzin et al., 1989; United States National Library of Medicine, 2002) ; some but not all medical libraries use this information to advise readers of retractions or corrections in printed journals (Cooper, 1992; Freeman \& Spurlock, 1986; Viera, 2000; Walter, 2000). In other libraries, such intervention may be considered improper or not integral to service quality (Hernon and Altman, 1995; Pfeifer and Snodgrass, 1992). Work in the past decade suggests that even for the serious situation of retractions in biomedical journals, published and indexed retractions are not sufficient to prevent widespread continued citation of retracted literature (Budd et al., 1998; Whitely et al., 1994). In addition to ordinary mistakes, instances of major scientific misconduct and fraud currently under discussion serve as reminders that the integrity of communication is always subject to question. As it is easier to change a uniquelyheld online file than thousands of widely-distributed printed copies, the fixity of published content - once virtually unquestioned - is no longer a given (Plutchak, 2002). A published article, however, is a historical record of priority, among its other roles. When the content of the original article is actually changed or withdrawn, the process has failed to preserve the historical record. Published corrections and retractions provide a way to add information to the historical record without altering the original communication. The development of online journals and hypertext linkages has given publishers the opportunity to bring errata, retractions, and similar subsequent material directly to readers of the original online article. Thus, the potential exists to 
improve scientists' awareness of these subsequent findings, reducing the repetition of known errors while preserving the original online version intact for the historical record.

In the physical sciences, errata and retractions have not commanded the level of attention seen in biomedical information. There is, however, certainly a need to be aware of them: reproducibility of experiments is essential, laboratory safety requires detailed attention to methods, the publication of standard data in primary literature demands a high degree of accuracy, and scientific misconduct does occur. The creation of "See" references to corrections for articles in print journals has been conducted for at least fifteen years at the University of New Hampshire Physics Library. Despite competing needs, this service has been retained due to faculty appreciation. With the advent of new technologies, it became clear that linking between original primary articles and errata would be possible. A view of current practice as embodied in the journals is essential to developing an understanding of how accessible this information is and in what ways it can be made more accessible to researchers. The present study fills a gap in published information about current practice by describing online access to errata from the user's perspective. Errata rather than retractions are the subject of this study, both to ensure a sufficient number of comparable examples across journals and to focus on the presence or absence of links rather than the merits of particular articles.

\section{Methodology}

The primary question addressed by this study was how, in practice, are article corrections (errata) identified and linked in online physical sciences journals. In order to answer this 
question from an empirical standpoint, we developed methods for locating published errata and examining errata and original articles online. We also explored alternative methods such as abstracting and indexing tools for finding errata.

\section{$\underline{\text { Selection of Journal Set }}$}

ISI's Journal Citation Reports on CD-ROM for 1994, 1998, and 2000 were used to select an initial set of major journals in the fields of Chemistry, Physics, and Astronomy and Astrophysics. For Physics, the categories Physics; Applied Physics; Atomic, Molecular and Chemical Physics; Condensed Matter Physics; Physics, Fluids and Plasmas; Mathematical Physics; Nuclear Physics; Physics, Particles and Fields; and Optics were applied together as a filter. For Physics, most journals were selected from the 1994 and 1998 top 70. The Chemistry and Astronomy and Astrophysics journals were then added, using JCR 2000. For Chemistry, the categories Analytical, Applied, Inorganic and Nuclear, Medicinal, Multidisciplinary, Organic, and Physical, plus Spectroscopy, were applied together as a filter. The criteria for journals selected for this study were impact factor, balance of review and non-review articles, publisher, availability of online versions, and accessibility. Three electronic-only journals were deliberately added to the set. Two recent physical sciences journal bibliographies (Fosmire \& Yu, 2000; Stankus et al., 1999) were used to supplement the information in JCR. After an initial phase of study, the journal set was revised to ensure that at least three journals per publisher were examined, if feasible. Institutional online access was provided by libraries at the University of New Hampshire and Massachusetts Institute of Technology. In addition to the journals, the treatment of article versions and errata on the arXiv eprint server (arXiv.org, 1991) was examined. 
$\underline{\text { Location of Errata }}$

For each journal studied, tables of contents were examined for errata, starting with the most recent complete online issue and working back until three errata had been located. In some cases, three errata were not available within the online issues; in those cases the only errata available online were used. If errata were not found, Science Citation Index on CD-ROM or on the Web of Science interface was searched to double check whether errata had been published in the time period examined. In a few cases, the corresponding print issue was consulted to resolve a lack of agreement between the journal and index.

\section{$\underline{\text { Examination of Online Treatments }}$}

For each erratum, all linkable formats were checked for the presence of links to the original article. These included HTML abstracts, HTML full-text articles, and PDF articles. Articles in Postscript format were offered by some publishers in addition to HTML or PDF versions, but were not separately examined. For each erratum, whether linked or not, the corresponding original article in all linkable forms (including HTML abstract and HTML and PDF full-text) was examined for links to the erratum. For full-text articles, examination was limited to the first page of the article and the portion from the end of the conclusion to the end of the reference list. The first erratum from each journal was also checked against the original article to establish whether the online article had been corrected. 


\section{$\underline{\text { Retrieval from Abstracting and Indexing Resources }}$}

We also assessed the ease of finding errata in literature searches, focusing on indexing of errata. For each journal studied, we examined the retrieval of errata via the publisher's or journal's own online searching facility and at least one independent index or abstract database. Selected terms such as "erratum" were used for general searching; author names, title words, and/or source journal were used for known-item searching to identify successful strategies for the specific resource. Independent services included: Web of Science, $\underline{\text { Science Citation Index }}$ on CD-ROM, INSPEC $\underline{\text { Ondisc, }}$ SciFinder Scholar, and Chemical Abstracts (CA) on STN.

Results and Discussion

The observations which follow were made from January to August, 2002. Because live online interfaces were used for this study, subsequent software updates, database additions, or edits may change the sites on which these observations were made. Screens were printed or downloaded at the time of observations to preserve results as they stood. A complete list of the errata and original articles examined, with URLs for all formats, is available, upon request, from the author.

Fifty journals were initially selected and examined online according to the method above. Seven journals were later excluded due to comparative lack of accessible online errata: Annalen der Physik; Chemical Vapor Deposition; Critical Reviews in Solid State and Materials Sciences; JHEP: Journal of High Energy Physics; Journal of Physical and Chemical Reference Data; Materials Science and Engineering: R, Reports, and MRS Bulletin. The remaining 43 journals are listed in Table 1. 
Although publishers use several terms to refer to errata, including erratum, corrigendum, and correction, the term erratum will be used throughout this discussion to refer to any published note of correction. The errata examined were limited to those published as part of or within the context of regular, numbered journal issues; separately-published print errata were not included in this study. Two of the types of online errata described do follow a model akin to separatelypublished errata, but were retained because of the difference in online publication.

\section{$\underline{\text { Linking }}$}

Major disparities were observed in the linking of original articles with errata, both between publishers and in some cases within a publisher's journal set. Cases varied from no links at all to consistent back-and-forth linking. Consistency of linking and presentation varied, mainly by publisher. Of the 43 journals reviewed in the study, 26 included at least one observed link connecting errata with original articles. Of these 26 journals, 14 linked back and forth between all of the observed errata and the articles to which they referred. There were no links observed between errata and original articles in 17 of the journals examined. Variations in linking and consistency for journals that provided links are shown in Table 2. Journals with no observed links are listed in Table 3. The practice of linking appeared better-established for certain publishers than others; evidence of this is seen in the checked "Yes" and "No" columns in Table 2. The journal sample from each publisher was too small to generalize beyond these particular observations. 
Publishers have developed diverse approaches to the challenges of labeling and placement of the links. Their solutions have implications for librarians and others who are implementing full-text targeting strategies such as SFX.

Links to or from errata were observed in the following non-exclusive positions:

1. Original article HTML abstracts (point-of-entry pages): 21 journals

2. Original article HTML full-text (first page): 7 journals

3. Errata HTML abstracts (point-of-entry pages): 12 journals

4. Errata HTML full-text: 11 journals

5. Tables-of-contents entries for original articles and errata: 2 journals (Academic)

6. List accessible from journal home page: 3 journals (Annual Reviews)

7. Linking from PDF, either original articles or errata: 0 journals

The primary styles for linking original articles to errata were as follows: 
1. Link included as an integral part of the article's abstract or point-of-entry page. This style is used by the American Institute of Physics ("See also" note), American Physical Society ("See also" note), Elsevier ("Referred to by" note), Institute of Physics (linked citation in phrase), and Optical Society of America (ㅁtics Letters, "Forward References" citation).

Example from Journal of Chemical Physics:

http://ojps.aip.org/getabs/servlet/GetabsServlet?prog=normal\&id=JCPSA6000115000020009113 $\underline{000001 \& \text { idtype }=\text { cvips \&gifs }=\text { yes }}$

2. Links placed separately, either horizontally at the top of the page or in a sidebar inset next to the article abstract or first page of full text. This is done by Academic Press, the American Chemical Society, Annual Reviews, and the Royal Society of Chemistry.

Example from the New Journal of Chemistry: http://www.rsc.org/CFmuscat/intermediate_abstract.cfm?FURL=/ej/NJ/1999/J9808808.PDF\&T $\underline{\mathrm{YP}=003}$

3. Linked phrase inserted that refers to the erratum on the first full-text page of the article, above the title (HTML only). Used by Macmillan (Nature) and Springer ( Inorganic Chemistry, JBIC). Example from JBIC, article link (subscribers only): $\underline{\text { http://link.springer- }}$ ny.com/link/service/journals/00775/contents/01/00266/paper/s007750100266ch000.html Example from JBIC, abstract link: http://link.springer-ny.com/link/service/journals/00775/contents/01/00266/index.html 4. Direct link added to the erratum at the table-of-contents entry for the original article. This is done in addition to abstract-level linking by Academic Press. 
Example from Journal of Magnetic Resonance Spectroscopy, see third entry from bottom of page:

http://www.idealibrary.com/links/toc/jmre/150/1/0

\section{$\underline{\text { Inconsistencies and Glitches }}$}

The several types of inconsistencies observed may reflect differences in either publishers' policies or practices over time or problems related to online journal production. These glitches were common enough to be evident even within the context of this limited study. Examples of inconsistencies include missing material: in one case, several errata were missing from online issues of journals that generally do include them; in another, an original article was missing from the online issue; in a third example, the issue's preliminary pages (to which the erratum referred) were not available online. These absences meant that errata could not be found either by browsing or by using the online journal's search engine. The absence of errata from some of the journal issues was only noticed when erratum lists derived from tables of contents were

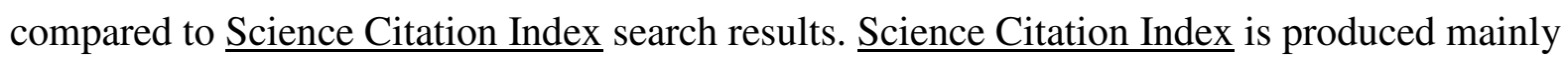
from printed journal versions. Some publishers were inconsistent in their approach to identifying errata in journal tables of contents. While not as serious as the missing matter, this inconsistency is confusing and may affect journal search engine retrieval. This problem took two basic forms. In one, an identifying section heading such as "Errata" or "Corrections" was employed only some of the time. In the second type, no heading was used. Instead, the table of contents entry was comprised of the publisher's chosen term for errata (usually "erratum" or "correction") in combination with the title of the original article, for example, "Erratum to "Why matter matters...." In some cases, this identifying term was not included, so that the original title 
became the table of contents entry. These types of problems have also been noted with respect to errata in the print environment (Hutchinson, 1994). Lastly, and truly an online issue, a few links failed: they either linked to the wrong file or failed to resolve.

We observed inconsistencies in the first three errata-original article pairs for the journal

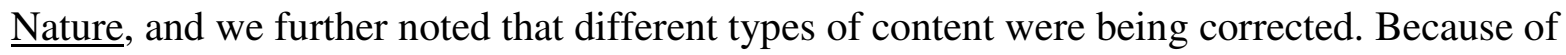
these observations, and since Nature is one of the most important scientific journals, we expanded the set of errata and original articles, conducting two more searches in order to build a larger set of errata-original pairs. The Nature search engine was used to retrieve the term "corrections." Then, the terms "errata" and "corrigenda" were searched together as "errata or corrigenda." Errata listed on the first page of each of the two hit sets and the corresponding original articles were checked, for a total of eighteen pairs (two of the "corrections" were false drops). Of these, three original articles were linked to their errata. All but one of the errata were linked to the corresponding originals unless the original pre-dated the online archive.

A model akin to separately-published errata has been employed by the Annual Reviews and the RSC online journals. In these periodicals, the errata are not published online as part of a particular volume or issue. Besides the linking that is present in the original articles and their abstracts, the Annual Reviews periodicals use a listing of errata accessible from each review journal's home page. The RSC online journals incorporate a link to the erratum from the original article's point-of-entry page. Errata are not included as separate entries in the online issues; thus, citations to print errata do not correspond to online versions. 


\section{$\underline{\text { E-Print Server Errata }}$}

Finally, because researchers in some fields now use it almost exclusively in preference to journals, we compared errata in the arXiv e-print server with online journal errata. Using known, published journal errata, three e-prints from the High Energy Physics - Phenomenology (hep-ph) section were retrieved and compared with the corresponding published journal errata. In all three cases authors had revised the papers, providing full versions of the original and corrected papers. The arXiv interface provides a point-of-entry level in which the revised and original versions of an article are listed and can be displayed. Searching the hep-ph listings for the terms "errata" or "erratum", one erratum was found. This erratum was posted by the third author separately from earlier revised and original versions of the article that were also available on arXiv. Only the originally-registered author is permitted to submit new versions or "replacements" (arXiv.org, 1991). Thus, it should not be assumed that all article revisions are available through the entry for the original posting.

\section{Indexing}

Retrieval of errata was tested in journal or publisher search engines and in independent abstracting and indexing sources. Most of the journal or publisher search engines explored in this study have the advantage of being freely available. However, they reflect the online content, which has been found to be inconsistent in some cases. In addition, while some retrieve articles and errata alike with author name searching, others cannot. This may be due to variations in whether author information is included in the table of contents and how it is given in the erratum itself. Overall, the most reliable indexing source for errata in this journal set was $\underline{\text { Science }}$ $\underline{\text { Citation Index }}$ (SCI). Since our group of journals was mainly developed using Journal Citation 
$\underline{\text { Reports, }}$ which is based on SCI data, all of our journals were indexed in SCI. There were individual missing citations, but the only systematic problem was related to the RSC journal errata. Because SCI indexing is based on print for most journals, and RSC online errata are not included in the corresponding issue, the print errata citations for these journals were not useful in locating the errata online. There are two basic ways to retrieve errata with SCI. First, a Cited Reference search can be conducted, using the citation to the original article. Errata will normally be listed as citing references for the original work. Another convenient way to retrieve errata is to perform a General Search using the journal title, author's name, and limiting to the document types "Corrections" and "Corrections, Additions.” If the author's name presents a retrieval problem, the search can often be limited by year as well as document type to yield a reasonably small result set.

Of the other indexes, INSPEC ondisc retrieved no hits for several recent known errata; INSPEC confirmed that it does not presently index errata (INSPEC communication, July 30, 2002). SciFinder Scholar, a natural language interface for the Chemical Abstracts Service (CAS) database $\underline{\mathrm{CAplus}}$, other CAS databases, and $\underline{\text { Medline, }}$ likewise retrieved no hits for known errata and no hits on the terms "erratum" and "errata." CAS confirmed that these terms are considered transition terms and are essentially ignored by SciFinder's natural language software (F. Glasser, personal communication, January 4, 2002). However, errata are indexed in CAplus and can be retrieved by searching it via STN. Searching with the Physics and Astronomy Classification System (PACS) code for errata, used by the AIP and APS journals, resulted in excellent retrieval of errata in the SPIN database. 


\section{Conclusions}

While links were present for over half of the observed journals, it was difficult to evaluate their usefulness. Transparency is lacking in some of the online interfaces; readers may not realize that "Forward references," "Referred to by," and "See also" are links that they should follow for corrected article information. Those implementing full-text linking software should note the frequent use of point-of-entry pages for supplementary links, so that this added information is not bypassed. The disparities among journals are confusing and suggest that a standard phrase and accepted location for these links would be helpful to both readers and those implementing full-text linking from bibliographic databases. The development of a standard format for errata could involve publishers, database producers, researchers, librarians and would ultimately benefit all groups. The unevenness in indexing and retrieval of errata with standard physical sciences literature searching tools makes a case for improved coverage, more detailed online user documentation, and even aggressive user education, as Pfeifer and Snodgrass have remarked (1992). But the implementation of links in the online primary record will do more to benefit scientific research than any of the indexing tools. Caveat lector!

In terms of future directions, it would be helpful to develop a better understanding of the inconsistencies observed in this study and the reasons behind them. Even more important in searching is a knowledge of what we should expect to find. Thus, investigation of publishers' policies and internal practices concerning online articles and errata, which are not widely disseminated, would also be a fruitful avenue for future research. 
The author is grateful to David M. Lane for many thoughtful discussions; to Gale Eaton, Dana Roth, and Tony Stankus for ideas and encouragement; to the reference librarians at the MIT Science Library for their assistance, to Paul and Evan Poworoznek for their strong support, and to the organizers of the $7^{\text {th }}$ Quadrennial Tri-Society Symposium, at which a preliminary report on this research was delivered on June 9, 2002 in Los Angeles, California. Travel support was provided by the UNH Library and UNH Faculty Development Fund. 


\section{References}

arXiv.org e-Print Archive Help (Uploads). (2000) [On-line] Available at: http://arXiv.org/help/uploads\#replace

Budd, J. M., Sievert, M., \& Schultz, T. R. (1998). Phenomena of retraction: Reasons for retraction and citations to the publications. Journal of the American Medical Association [Online] , 280(3). Available: http://jama.ama-assn.org/issues/v280n3/rfull/jpv71004.html

Cooper, E. R. (1992). Identifying errata and retractions: Simplified approaches for serials management. Serials Review, 18(4), 17-20.

Fosmire, M., \& Yu, S. Free scholarly electronic journals: How good are they? Issues in

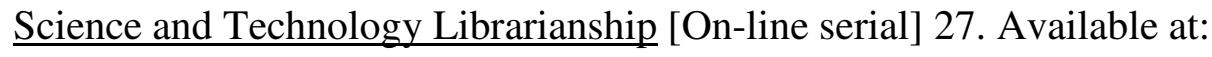
http://www.library.ucsb.edu/istl/00-summer/refereed.html

Freeman, I. \& Spurlock, S. (1986). Management of journal errata in a health sciences library. Medical Reference Services Quarterly 5(1), 41-49.

Hernon, P., \& Altman, E. (1995). Misconduct in academic research: Its implications for the service quality provided by university libraries. Journal of Academic Librarianship, 21(1), 27-37.

Hutchinson, T. P. (1994) Finding corrigenda to journal articles. Australian \& New Zealand Journal of Serials Librarianship, 4(4), 69-72.

Kotzin, S., \& Schuyler, P. (1989). NLM's practices for handling errata and retractions. Bulletin of the Medical Library Association, 77, 337-342.

Pfeifer, M. P., \& Snodgrass, G. L. (1992). Medical school libraries' handling of articles that report invalid science. Academic Medicine 67(2): 109-113. 
Plutchak, T. S. (2002). Editorial: sands shifting beneath our feet. Journal of the Medical Library Association [On-line], 90(2). Available:

http://pubmedcentral.gov/picrender.fcgi?artid=100760\&action=stream\&blobtype=pdf

Stankus, T., Clavin, J. M., \& R. Joslin. (1999). The best original scientific research, review, methods and symposia journals with their current web addresses ranked within their primary subject category. In T. Stankus, Electronic expectations: science journals on the Web (pp. 111-182). New York: Haworth Press.

U. S. National Library of Medicine. (2002). Fact sheet: errata, retraction, duplicate publication, and comment policy [On-line]. Available:

http://www.nlm.nih.gov/pubs/factsheets/errata.html

Viera, A. (2000). Marking retracted papers at The Webster Pendergrass Agriculture Veterinary Medicine Library. Bulletin of the Medical Library Association [On-line], 88(3). Available: http://pubmedcentral.gov/picrender.fcgi?action=stream\&blobtype=pdf\&artid=35240 Walter, G. "Rubber stamping" retracted papers. Bulletin of the Medical Library Association [On-line], 88(1). Available:

http://www.pubmedcentral.gov/articlerender.fcgi?artid=35205

Whitely, W. P., Drummond, R., \& Hafner, A. W. (1994). The scientific community’s response to evidence of fraudulent publication: The Robert Slutsky case. Journal of the American Medical Association [On-line], 272:170-173. Available: http://www.amaassn.org/public/peer/7_13_94/pv3111x.htm 
Table 1.

Final Group of Journals Analyzed for Errata Treatments.

\begin{tabular}{|c|c|}
\hline Publisher & Journal \\
\hline \multirow[t]{3}{*}{ Academic Press } & Annals of Physics (NY) \\
\hline & Atomic Data and Nuclear Data Tables \\
\hline & Journal of Magnetic Resonance \\
\hline \multirow[t]{3}{*}{ American Chemical Society } & Analytical Chemistry \\
\hline & Chemical Reviews \\
\hline & Journal of the American Chemical Society \\
\hline \multirow[t]{3}{*}{ American Institute of Physics } & Applied Physics Letters \\
\hline & Journal of Applied Physics \\
\hline & Journal of Chemical Physics \\
\hline \multirow[t]{3}{*}{ American Physical Society } & Physical Review D \\
\hline & Physical Review Letters \\
\hline & Reviews of Modern Physics \\
\hline \multirow[t]{3}{*}{ Annual Reviews, Inc. } & Annual Review of Astronomy and Astrophysics \\
\hline & Annual Review of Fluid Mechanics \\
\hline & Annual Review of Nuclear and Particle Science \\
\hline Blackwell Publishing & Geophysical Journal International \\
\hline \multirow[t]{4}{*}{ Elsevier } & Nuclear Physics B \\
\hline & Physics Letters B \\
\hline & Physics Reports \\
\hline & Progress in Nuclear Magnetic Resonance Spectroscopy \\
\hline
\end{tabular}




\begin{tabular}{|c|c|}
\hline \multirow[t]{3}{*}{ IEEE } & IEEE Journal of Quantum Electronics \\
\hline & IEEE Photonics Technology Letters \\
\hline & IEEE Transactions on Plasma Science \\
\hline \multirow{3}{*}{ Institute of Physics Publishing } & Journal of Physics B \\
\hline & Reports on Progress in Physics \\
\hline & Superconductor Science and Technology \\
\hline \multirow[t]{4}{*}{ Kluwer } & Journal of Biomolecular NMR \\
\hline & Journal of Atmospheric Chemistry \\
\hline & Solar Physics \\
\hline & Space Science Reviews \\
\hline Macmillan & Nature \\
\hline \multirow[t]{3}{*}{ Optical Society of America } & Journal of the Optical Society of America. A \\
\hline & Optics Express \\
\hline & Optics Letters \\
\hline \multirow[t]{3}{*}{ Royal Society of Chemistry } & Chemical Communications \\
\hline & Faraday Discussions \\
\hline & New Journal of Chemistry \\
\hline \multirow[t]{3}{*}{ Springer-Verlag } & Journal of Biological Inorganic Chemistry \\
\hline & Theoretical Chemical Accounts \\
\hline & European Physical Journal C \\
\hline \multirow[t]{3}{*}{ Wiley } & Angewandte Chemie, International Edition \\
\hline & Chemistry, A European Journal \\
\hline & Journal of Computational Chemistry \\
\hline
\end{tabular}


Table 2.

$\underline{\text { Variations of Online Links Between Errata and Original Articles }}$

\begin{tabular}{|c|c|c|c|c|c|c|c|}
\hline \multirow[b]{3}{*}{ Publisher } & \multirow[b]{3}{*}{ Journal } & \multicolumn{6}{|c|}{ Presence of links } \\
\hline & & \multicolumn{3}{|c|}{ Article to erratum } & \multicolumn{3}{|c|}{ Erratum to article } \\
\hline & & Yes & Some & No & Yes & Some & No \\
\hline \multirow[t]{4}{*}{ Academic Press } & Annals of Physics & & 2 of 3 & & & 2 of 3 & \\
\hline & Atomic Data and Nuclear Data & & & $\mathrm{X}$ & & & $\mathrm{X}$ \\
\hline & Tables & & & & & & \\
\hline & Journal of Magnetic Resonance & $\mathrm{X}$ & & & $\mathrm{X}$ & & \\
\hline \multirow[t]{4}{*}{ American Chemical Society } & Analytical Chemistry & & & $X$ & $X$ & & \\
\hline & Chemical Reviews & & & $\mathrm{X}$ & & 2 of 3 & \\
\hline & Journal of the American Chemical & & & $X$ & $X$ & & \\
\hline & Society & & & & & & \\
\hline \multirow[t]{3}{*}{ American Institute of Physics } & Applied Physics Letters & $\mathrm{X}$ & & & $\mathrm{X}$ & & \\
\hline & Journal of Applied Physics & $\mathrm{X}$ & & & $X$ & & \\
\hline & Journal of Chemical Physics & $\mathrm{X}$ & & & $\mathrm{X}$ & & \\
\hline
\end{tabular}




\begin{tabular}{|c|c|c|c|c|c|}
\hline \multirow[t]{3}{*}{ American Physical Society } & Physical Review D & $\mathrm{X}$ & & $\mathrm{X}$ & \\
\hline & Physical Review Letters & $\mathrm{X}$ & & $\mathrm{X}$ & \\
\hline & Reviews of Modern Physics & 2 of 3 & & $\mathrm{X}^{\mathrm{a}}$ & \\
\hline \multirow[t]{6}{*}{ Annual Reviews } & Annual Review of Astronomy and & $\mathrm{X}$ & & $\mathrm{X}$ & \\
\hline & Astrophysics $^{\mathrm{b}}$ & & & & \\
\hline & Annual Review of Fluid & $\mathrm{X}$ & & $\mathrm{X}$ & \\
\hline & Mechanics $^{b}$ & & & & \\
\hline & Annual Review of Nuclear and & $\mathrm{X}$ & & $\mathrm{X}$ & \\
\hline & Particle Science & & & & \\
\hline Blackwell Publishing & Geophysical Journal International & & $\mathrm{X}$ & & $\mathrm{X}$ \\
\hline \multirow[t]{5}{*}{ Elsevier } & Nuclear Physics B & $\mathrm{X}$ & & $\mathrm{X}$ & \\
\hline & Physics Letters B & $\mathrm{X}$ & & $\mathrm{X}$ & \\
\hline & Physics Reports & & $\mathrm{X}$ & & $\mathrm{X}$ \\
\hline & Progress in Nuclear Magnetic & & $\mathrm{X}$ & & $\mathrm{X}$ \\
\hline & Resonance Spectroscopy ${ }^{\mathrm{b}}$ & & & & \\
\hline Institute of Physics & Journal of Physics B & $\mathrm{X}$ & & $\mathrm{X}$ & \\
\hline
\end{tabular}




\begin{tabular}{|c|c|c|c|c|c|c|c|}
\hline & Reports on Progress in Physics & & 2 of $3^{d}$ & & & 2 of $3^{\mathrm{d}}$ & \\
\hline & Superconductor Science and & $\mathrm{X}$ & & & $\mathrm{X}$ & & \\
\hline & Technology & & & & & & \\
\hline Macmillan & Nature $^{c}$ & & 1 of 3 & & $\mathrm{X}$ & & \\
\hline \multirow[t]{4}{*}{ Optical Society of America } & Journal of the Optical Society of & & & $\mathrm{X}$ & & & $\mathrm{X}$ \\
\hline & America. A & & & & & & \\
\hline & Optics Express & & & $\mathrm{X}$ & & 2 of $3^{a}$ & \\
\hline & Optics Letters & $\mathrm{X}$ & & & $\mathrm{X}$ & & \\
\hline \multirow[t]{3}{*}{ Royal Society of Chemistry } & Chemical Communications & & 2 of $3^{\mathrm{d}}$ & & & $\mathrm{n} / \mathrm{a}^{\mathrm{e}}$ & \\
\hline & Faraday Discussions & $\mathrm{X}$ & & & & $\mathrm{n} / \mathrm{a}^{\mathrm{e}}$ & \\
\hline & New Journal of Chemistry & $\mathrm{X}$ & & & & $\mathrm{n} / \mathrm{a}^{\mathrm{e}}$ & \\
\hline \multirow[t]{4}{*}{ Springer-Verlag } & Journal of Biological Inorganic & & 1 of 3 & & $X^{a}$ & & \\
\hline & Chemistry & & & & & & \\
\hline & Theoretical Chemistry Accounts & & & $\mathrm{X}$ & & & $\mathrm{X}$ \\
\hline & European Physical Journal C & & & $\mathrm{X}$ & & & $\mathrm{X}$ \\
\hline
\end{tabular}


Note. $\mathrm{X}$ indicates that all pairs were linked. At least three errata-original pairs were checked for each journal

unless noted.

${ }^{\mathrm{a}}$ Not all observed links worked.

${ }^{b}$ When checked, only two errata were available online for this journal.

${ }^{c}$ These are partial results for comparison only; Nature errata were the subject of additional study, reported

elsewhere in this article.

${ }^{\mathrm{d}}$ Unlinked erratum corrected an error that was only present in the print version.

${ }^{\mathrm{e}}$ Errata are not included as separate entries in RSC online journal issues, only as files linked from original article abstracts. 
Table 3.

Journals Lacking Observed Links Between Errata and Original Articles

\begin{tabular}{|c|c|}
\hline Publisher & Journal \\
\hline Academic Press & Atomic Data and Nuclear Data Tables \\
\hline Blackwell Publishing & Geophysical Journal International \\
\hline \multirow[t]{2}{*}{ Elsevier } & Physics Reports \\
\hline & Progress in Nuclear Magnetic Resonance Spectroscopy \\
\hline \multirow[t]{3}{*}{$\mathrm{IEEE}^{\mathrm{a}}$} & IEEE Journal of Quantum Electronics \\
\hline & IEEE Photonics Technology Letters \\
\hline & IEEE Transactions on Plasma Science \\
\hline \multirow[t]{4}{*}{ Kluwer $^{\mathrm{a}}$} & Journal of Atmospheric Chemistry ${ }^{b}$ \\
\hline & Journal of Biomolecular NMR ${ }^{\mathrm{b}}$ \\
\hline & Solar Physics \\
\hline & Space Science Reviews \\
\hline Optical Society of America & Journal of the Optical Society of America A \\
\hline \multirow[t]{2}{*}{ Springer-Verlag } & European Physical Journal C \\
\hline & Theoretical Chemistry Accounts \\
\hline \multirow[t]{3}{*}{ Wiley $^{\mathrm{a}}$} & Angewandte Chemie, International Edition \\
\hline & Chemistry, A European Journal \\
\hline & Journal of Computational Chemistry \\
\hline
\end{tabular}


Note. At least three errata-original pairs were checked for each journal unless noted.

${ }^{a}$ No links to or from errata were observed in any of the selected journals of this publisher.

${ }^{\mathrm{b}}$ At the time of these observations, this journal had fewer than three errata available online. 